\title{
The use of rRNA sequences and fluorescent probes to investigate the phylogenetic positions of the anaerobic ciliate Metopus palaeformis and its archaeobacterial endosymbiont
}

\author{
T. Martin Embley, ${ }^{*}$ Bland J. Finlay, ${ }^{2}$ Richard H. Thomas ${ }^{3}$ and Patricia L. Dyal ${ }^{1}$ \\ ${ }^{1,3}$ Microbiology Group ${ }^{1}$ and Molecular Biology Unit ${ }^{3}$, Department of Zoology, The Natural History Museum, \\ Cromwell Road, London SW7 5BD, UK \\ ${ }^{2}$ Institute of Freshwater Ecology, Windermere Laboratory, Far Sawrey, Ambleside, Cumbria LA22 OLP, UK
}

(Received 13 January 1992; revised 23 March 1992; accepted 31 March 1992)

\begin{abstract}
The polymerase chain reaction (PCR) was used to amplify small-subunit ribosomal DNA from the anaerobic ciliated protozoon Metopus palaeformis, and from its uncultured endosymbiotic bacteria. This was accomplished directly from total DNA extracted from protozoa without prior isolation or enrichment for symbiont cells. The double-stranded amplification products were precipitated and directly sequenced using the linear PCR reaction. Fluorescent oligonucleotide probes were designed and used in whole-cell hybridizations to provide direct visual evidence that the sequences originated from the host ciliate and from the endosymbiont. Phylogenetic analysis of the Metopus palaeformis sequence consistently placed it as a deep-branching lineage near the root of the ciliate tree. However, the present data were insufficient to resolve the detailed relationship between Blepharisma and Metopus and thus to determine if the heterotrichs are mono- or paraphyletic. Phylogenetic analysis of the symbiont partial sequence clearly demonstrated that it is an archaeobacterium and that it is closely related to, but distinct from, Methanobacterium formicicum.
\end{abstract}

\section{Introduction}

Comparative sequencing of ribosomal RNA has revolutionized studies in microbial classification and provided a framework for interpreting natural diversity (Woese, 1987). Methods based on RNA analyses are increasingly being used in studies of environmental microbiology (Olsen et al., 1986; Stahl et al., 1988; DeLong et al., 1989; Amman et al., 1990, 1991). For example, the polymerase chain reaction (PCR) (Saiki et al., 1988) and the development of methods for probing single cells (Giovannoni et al., 1988; DeLong et al., 1989) mean that it is now possible to investigate the evolutionary relationships of uncultured micro-organisms (Amman et al., 1991; Fry et al., 1991). The rRNA genes from eukaryotes, bacteria and archaeobacteria have been shown to vary significantly in their primary sequence (Woese, 1987; Neefs et al., 1991). It is thus relatively simple to design PCR primers that will

* Author for correspondence. Tel. (071) 9388760 ; fax (071) 9388754 .

The nucleotide sequences determined in this work have been deposited in GenBank and have been assigned the accession numbers M86385 (M. palaeformis) and M86386 (endosymbiont). specifically amplify RNA sequences from particular phylogenetic groups directly from heterogeneous mixtures of templates (Giovannoni et al., 1990; Amman et al., 1991; Fry et al., 1991). Having obtained the sequences, fluorescent probes can be designed and used in whole-cell hybridization experiments, thereby linking the sequence to a defined morphotype (Edman et al., 1988; Giovannoni et al., 1988; DeLong et al., 1989).

Metopus palaeformis is an anaerobic ciliate which is common in a variety of freshwater habitats and anaerobic municipal landfill (Finlay \& Fenchel, 1991). Its phylogenetic position among eukaryotes is uncertain but it is currently classified as a member of the class Spirotrichea, subclass Heterotrichia, on the basis of its oral and somatic infraciliature (Lynn \& Corliss, 1991). This group also contains Blepharisma americanum, which is currently the deepest-branching ciliate (Greenwood et $a l ., 1991 a, b$; Schlegel et al., 1991). Like many of the freeliving protozoa in anaerobic environments, members of the genus Metopus contain symbiotic methanogenic bacteria (Fenchel et al., 1977; Van Bruggen et al., 1984, 1986; Fenchel \& Finlay, $1991 a$; Finlay \& Fenchel, 1991). The symbionts of Metopus striatus and Metopus contortus have been isolated and tentatively identified (on the

0001-7329 C 1992 SGM 
basis of morphology and $\mathrm{G}+\mathrm{C}$ ratios) as Methanobacterium formicicum and Methanoplanus endosymbiosus, respectively (Van Bruggen et al., 1984, 1986). Metopus palaeformis contains a rod-shaped putative methanogen which has not been isolated and thus remains unidentified (Finlay \& Fenchel, 1991).

In the present investigation we have used PCR to amplify and directly sequence the small-subunit ribosomal DNA from Metopus palaeformis and from its endosymbiotic bacteria. Fluorescent probes were designed and used in whole-cell hybridizations to confirm the origins of the sequences. The sequences were then analysed in order to determine the phylogenetic positions of Metopus palaeformis and its endosymbiont.

\section{Methods}

The ciliate and its symbionts. The anaerobic ciliate Metopus palaeformis, containing symbiotic bacteria, was isolated from anoxic municipal landfill (Finlay \& Fenchel, 1991). The ciliates were maintained anaerobically, using the indigenous microbial flora as food (Fenchel \& Finlay, 1990). Cells of $\boldsymbol{M}$. palaeformis were purified from free-living archaeobacteria by electromigration. The electromigration device was identical to that described by Wagener et al. (1986) except for the insertion of a loose cotton wool plug in the capillary tube through which the ciliates were forced to swim. The isolated ciliates were suspended in anoxic (purged with $\mathrm{N}_{2}$ ), dithionite-reduced mineral medium (Wagener \& Pfennig, 1987; S. Wagener, personal communication) containing $\left(\mathrm{g} \mathrm{l}^{-1}\right): \mathrm{KH}_{2} \mathrm{PO}_{4}(0 \cdot 15), \mathrm{NH}_{4} \mathrm{Cl}(0.035), \mathrm{NaCl}(0 \cdot 4)$, $\mathrm{MgCl} .6 \mathrm{H}_{2} \mathrm{O}(0 \cdot 2), \mathrm{KCl}(0 \cdot 15), \mathrm{CaCl}_{2} .2 \mathrm{H}_{2} \mathrm{O}(0 \cdot 25), \mathrm{NaHCO}_{3}(1 \cdot 0)$, and adjusted to $\mathrm{pH} 7 \cdot 0$.

DNA extraction. Approximately $10^{4}$ ciliates were centrifuged at $4000 \mathrm{~g}$ for $5 \mathrm{~min}$ and washed once with distilled water before resuspending in $50 \mu \mathrm{l}$ sterile Millipure water. DNA was isolated using the rapid guanidium method devised by Pitcher et al. (1989), but omitting the Sarkosyl from the lysis reagent. The DNA was redissolved in $50 \mu \mathrm{l}$ sterile Millipure water and stored in $10 \mu \mathrm{l}$ aliquots at $-70^{\circ} \mathrm{C}$.

Selection of PCR primers. PCR primers were designed to selectively amplify archaeobacterial ( $1 \cdot 1 \mathrm{~kb}$ fragment) or eukaryotic (full-length), small-subunit ribosomal DNA. The sequences of the archaeobacterial primers were biased towards the methanogens and their close relatives (the Euryarchaeota; Woese et al., 1990). The primers were 1A forward (f) 5' TCYGKTTGATCCYGSCRGAG and $1100 \mathrm{~A}$ reverse (r) $5^{\prime}$ TGGGTCTCGCTCGTTG. The primers for the eukaryote small subunit rRNA sequences were forward primer 5' AYCTGGTTGATYYTGCCAG and reverse 5' TGATCCATCTGCAGGTTCACCT. These primers are essentially the same as those devised by Medlin $e t$ al. (1988) but without the polylinkers. The primers amplify almost the entire small subunit RNA sequence of most eukaryotes (Neefs et al., 1991). RNA sequences for the ciliate protozoa Colpidium campylum, Glaucoma chattoni, Opisthonecta henneguyi, Onychodromus quadricornutus, Oxytricha granulifera, Blepharisma americanum and Colpoda inflata were taken from published papers (Greenwood et al., 1991 $a, b$; Schlegel et al., 1991).

$P C R$ amplifications. Each amplification contained $2 \mu$ of template DNA solution, $10 \mu \mathrm{l}$ of PCR buffer $\left(670 \mathrm{~mm}\right.$-Tris/ $\mathrm{HCl}, 20 \mathrm{mM}-\mathrm{MgCl}_{2}$,

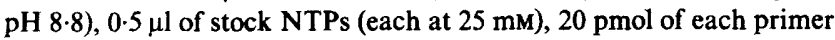
(either eukaryotic or archaeobacterial specific), 0.1 unit of Perfect Match Polymerase Enhancer (Promega) and sterile Millipure water to $98 \mu \mathrm{l}$. The tubes were heated to $95^{\circ} \mathrm{C}$ in a Hybaid TR2 Intelligent
Heating Block and $2 \mu \mathrm{l}$ (1 unit) of Taq polymerase (Cetus) was added to each tube, followed by $50 \mu \mathrm{l}$ of sterile mineral oil. The thermal programme comprised 10 cycles of denaturation at $94^{\circ} \mathrm{C}$ for $40 \mathrm{~s}$, hybridization at $55^{\circ} \mathrm{C}$ for $40 \mathrm{~s}$ and extension at $72^{\circ} \mathrm{C}$ for $2 \mathrm{~min}$. This was followed by 20 cycles of $92^{\circ} \mathrm{C}$ for $30 \mathrm{~s}, 55^{\circ} \mathrm{C}$ for $40 \mathrm{~s}$ and extension at $72{ }^{\circ} \mathrm{C}$ for $2.5 \mathrm{~min}$. A $6 \mathrm{~min}$ extension at $72{ }^{\circ} \mathrm{C}$ completed the programme.

Sequencing of amplified ribosomal DNA. The amplified material was sequenced using the linear PCR procedure described by Embley (1991). The archaeobacterial sequencing primers were 519 reverse (r) GWATTACCGCGGCKGCTG, 380r TTTCGCGCCTGCTGC and IAf. The eukaryote sequencing primers were taken from Elwood et al. (1985) and comprised 377 $\mathrm{r}$ TCAGGCTTCYTCTCCGG, 557r ACCGCGGCK GCTGGC, 892r AGAATTTCACCTCTG, $1262 \mathrm{r}$ CGGCCATGCACCACC, 1705r ACGGGCGGTGTGTRC and $1705 \mathrm{f}$ GYACACACCGCCCGT. The products of the sequencing reactions were analysed on standard wedge-shaped sequencing gels.

Data analysis. The primary sequence data for the symbiont and for Metopus palaeformis have been deposited in GenBank (M86386 and M86385).

The sequence for the endosymbiont was aligned by eye against sequences for reference archaeobacteria and corrected for known secondary structure (Neefs et al., 1991). Positions which could not be aligned unambiguously were omitted; the final data comprised 333 bases. Distance values were calculated using the method of Jukes \& Cantor (1969) contained in the DNADIST program (PHYLIP 3.4, J. Felsenstein, University of Washington, USA). A phylogenetic tree was generated by the neighbour-joining method (Saitou \& Nei, 1987), using Thermococcus celer as an outgroup (Woese et al., 1990).

The sequence for Metopus palaeformis was aligned by eye against 13 published sequences for ciliates, and the sequence for the dinoflagellate Prorocentrum micans, as an outgroup (Greenwood et al., $1991 a$; Neefs $e t$ al., 1991). The small-subunit RNA sequences of eukaryotes may show considerable variation in the length and sequence of certain domains such as region V4 (Neefs et al., 1991). In order to align the sequences from this region the secondary-structure models proposed by Nickrent \& Sargent (1991) and Neefs \& De Wachter (1990) were used. Sites where it was uncertain that truly homologous positions were being compared (approx. 200 bases), were omitted. A total of 1419 bases comprised the final alignment; this is available from the authors on request. In initial analyses, pairwise distance values between sequences were obtained using the Jukes \& Cantor (1969) correction for multiple substitutions (contained in DNADIST, version 3.4). The values obtained were generally less than $0 \cdot 2$ (the matrix is available on request). Since values in this range are unlikely to be significantly affected by the use of different substitution corrections (Jin \& Nei, 1990) only the Jukes \& Cantor (1969) correction was used. Phylogenetic trees were constructed from the distance matrix using either the neighbour-joining (Saitou \& Nei, 1987), or Fitch \& Margoliash (1967) methods contained in PHYLIP 3.4. In order to evaluate the robustness of the results, 100 bootstrap resamplings of the data were taken (SEQBOOT 3.4, PHYLIP) and neighbour joining performed on each sample. A consensus tree was produced using CONSENSE 3.4 (PHYLIP). Bootstrapped (100 times) maximum parsimony (PAUP 3.0q. Swofford, 1991) was also employed to analyse the data. In an effort to resolve the deeper internal branches of the ciliate phylogenetic tree, the linear invariants method of Lake (1987) was used (PAUP 3.0q). Since all methods of phylogenetic reconstruction are potentially biased by variation in base frequencies (Gillespie, 1986), a modification of Lake's method (Sidow \& Wilson, 1990 ), which attempts to correct for base compositional differences, was also used.

Design of probes. The sequence for the endosymbiont was compared to the sequence for Metopus palaeformis and to the published rRNA data base for archaeobacteria (Neefs et al., 1991). Two oligonucleotide 
probes were constructed, SYM1 5' AACCCGTACAGATCAAAGG and SYM2 5' GACCATTCCAGGAATCTCTA, to bind specifically to rRNA from the symbiont. The probes recognized sequences within helices 12 and 13 , and helix 10 , respectively, by reference to the Halobacterium cutirubrum secondary structure (Neefs et al., 1991). A probe (5' TTTACGTTTGGCCCATTC) was designed to bind exclusively to rRNA sequences (within helix 18; Neefs et al., 1991) of Metopus palaeformis. Control probes designed (Stahl \& Amman, 1991) to bind selectively to either archaeobacterial or eukaryote rRNA were also prepared. All of the probes were synthesized using Amino-link 2 (Applied Biosystems) and coupled to tetramethyl-6-carboxyrhodamine or 6-carboxyfluorescein (Applied Biosystems) using the manufacturer's protocols. Hybridization experiments were carried out at $48^{\circ} \mathrm{C}$ for 4-6h using procedures described by Stahl \& Amman (1991) with only slight modifications. The preparations were not prehybridized. Each hybridization was carried out on a standard 'subbed' microscope slide to which $20 \mu \mathrm{l}$ of hybridization solution containing $50 \mathrm{ng}$ of specific probe was added. A cover slip was applied and sealed to the slide using clear nail-varnish to retard evaporation.

Epifluorescence microscopy and photomicrography. After hybridization each slide was mounted using Citifluor antifadent (AF1, Citifluor Ltd, London) and examined using a Leica Aristoplan epifluorescence microscope fitted with filter sets specific for rhodamine or fluorescein. Photographs were taken on Kodak Ektachrome 400 ASA black and white film; exposures were controlled via a photoautomat MPS-46 attached to the microscope. Living ciliates were fixed with $4 \%(v / v)$ formaldehyde solution prior to preparation for observation of autofluorescing endosymbiotic methanogens (Finlay \& Fenchel, 1989).

Ciliates were prepared for electron microscopy as described by Finlay \& Fenchel (1991)

\section{Results and Discussion}

The products of the PCR reactions were examined using agarose gel electrophoresis. The reactions using the archaeobacterial primers gave a single weak band of about $1 \cdot 1 \mathrm{~kb}$. The reactions with the eukaryote primers produced a single strong band of approximately $1.7 \mathrm{~kb}$. The latter is in the size range which is frequently reported for ciliate small subunit rRNA genes (Greenwood et al., $1991 a, b$; Schlegel et al., 1991). No bands were observed in reactions lacking template. The amplified material was precipitated and directly sequenced (Embley, 1991). Each of the two sequences was unambiguous in regions of rRNA known to be highly variable (e.g. regions V2 and V4; Neefs et al., 1991). This strongly suggests that the eukaryote and archaeobacterial sequences were each derived from a single species.

The final number of bases of sequence from the product amplified using the eukaryote primers was 1624 . The sequence stretched from two bases downstream of the $3^{\prime}$ terminus of each PCR primer, with a small gap of 50 bases near to the base of helix 47 (Neefs et al., 1991). The PCR primers used in this investigation can bind to rRNA genes from most eukaryotes (including humans) and it is possible that PCR products could arise from contaminants. Furthermore, since unicellular eukaryotes are often classified solely on the basis of morphology
(Margulis et al., 1989) it is useful to be able to link a sequence to a cell type. Like most protozoa, Metopus palaeformis can demonstrate a variety of forms depending on its growth phase and nutritional status, and this can lead to difficulties in its identification (Finlay \& Fenchel, 1991). To prove that our sequence originated from Metopus palaeformis, and to demonstrate the utility of whole-cell probing for the identification of protozoa, a fluorescent probe was designed. Fig. $1(a)$ shows a phasecontrast image of a mixed field containing Metopus palaeformis and a selection of eukaryotes and prokaryotes. This preparation was simultaneously probed with a fluorescein-conjugated eukaryote specific oligonucleotide (Stahl \& Amman, 1991) and a Metopus palaeformis-specific oligonucleotide labelled with tetramethylrhodamine. Fig. 1(b) shows the same field under blue excitation for the fluorescein-labelled probe. All of the eukaryotic cells in the field, but none of the prokaryotes, show fluorescence. Fig. 1(c) shows the same field excited for tetramethylrhodamine, when only the single cell of Metopus palaeformis gives a signal. This clearly demonstrates that the eukaryotic sequence is from Metopus palaeformis. It also supports the use of fluorescent probes for the identification and enumeration of unicellular eukaryotes in mixed populations. The fluorescence is evenly distributed over the cell, allowing cell shape to be observed.

Ciliate phylogeny has traditionally been interpreted in terms of structural features of the cortex and of somatic and oral ciliature (Lynn \& Corliss, 1991). However, the complexities of ciliate architecture and the difficulties in distinguishing between ancestral and derived morphologies have produced a number of conflicting phylogenies (Lynn \& Corliss, 1991). The analysis of molecular sequence data can provide an independent test of conflicting hypotheses. Fig. 3 shows the relationships between Metopus palaeformis and reference ciliates based on small-subunit rRNA sequences. The dinoflagellate Prorocentrum micans was used as an outgroup. The tree illustrates the consensus topology (100 bootstrap replicates) obtained using the Jukes \& Cantor (1969) correction and the neighbour-joining method (Saitou \& Nei, 1987). The topology of the tree is very similar (for common species) to previously published distance trees based on SSrRNA (Greenwood et al., 1991 $a, b$; Schlegel et al., 1991). Thus the clades containing the stichotrichs and the hymenostomes, respectively, were strongly supported using the distance (Fig. 2) and parsimony methods (not shown). There was also support in all analyses for a relationship between Colpoda inflata, Paramecium tetraurelia, Opisthonecta henneguyi and the hymenostomes. Euplotes aediculatus was recovered on the branch leading to the stichotrichs in the distance and parsimony analyses and this is in agreement with 

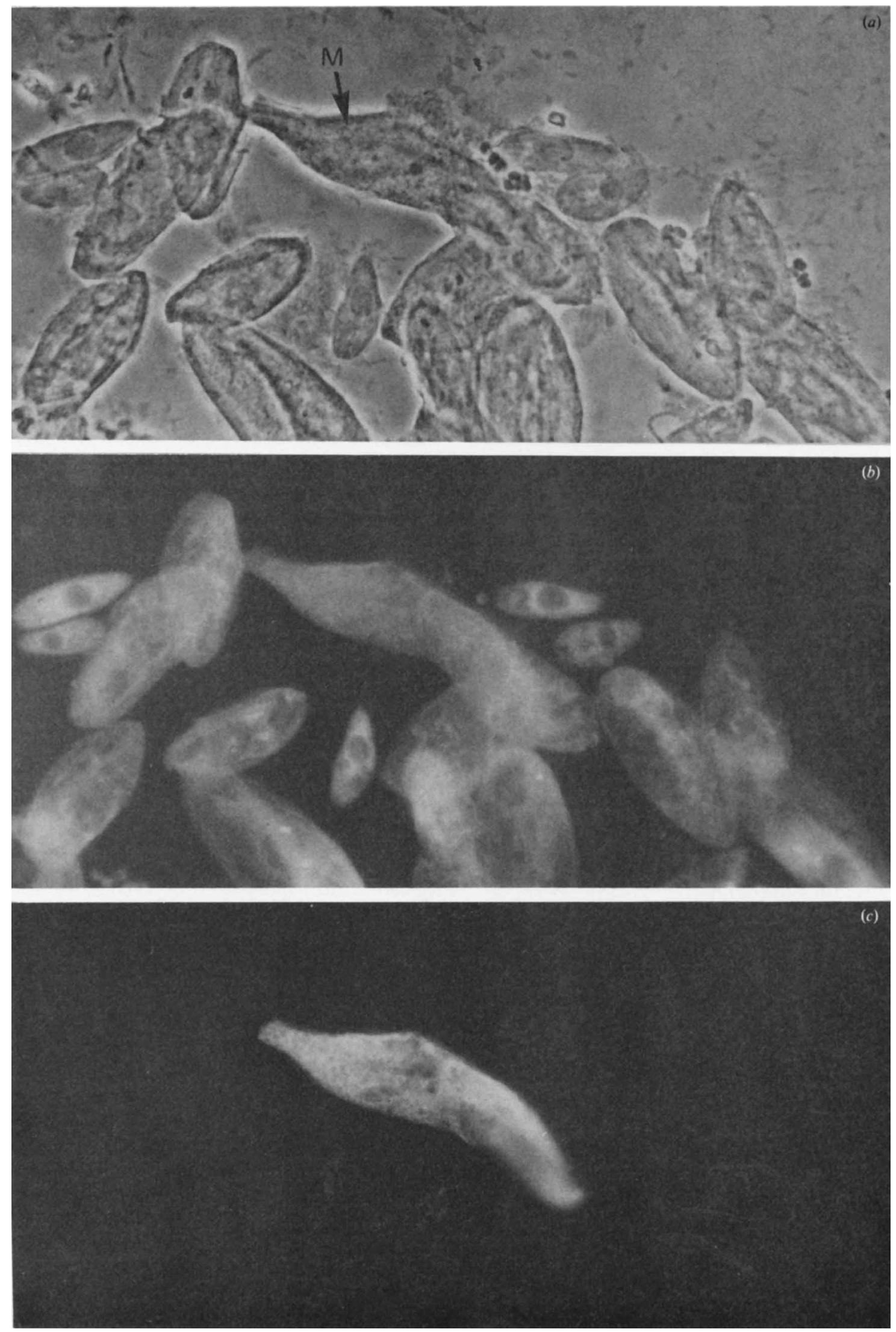


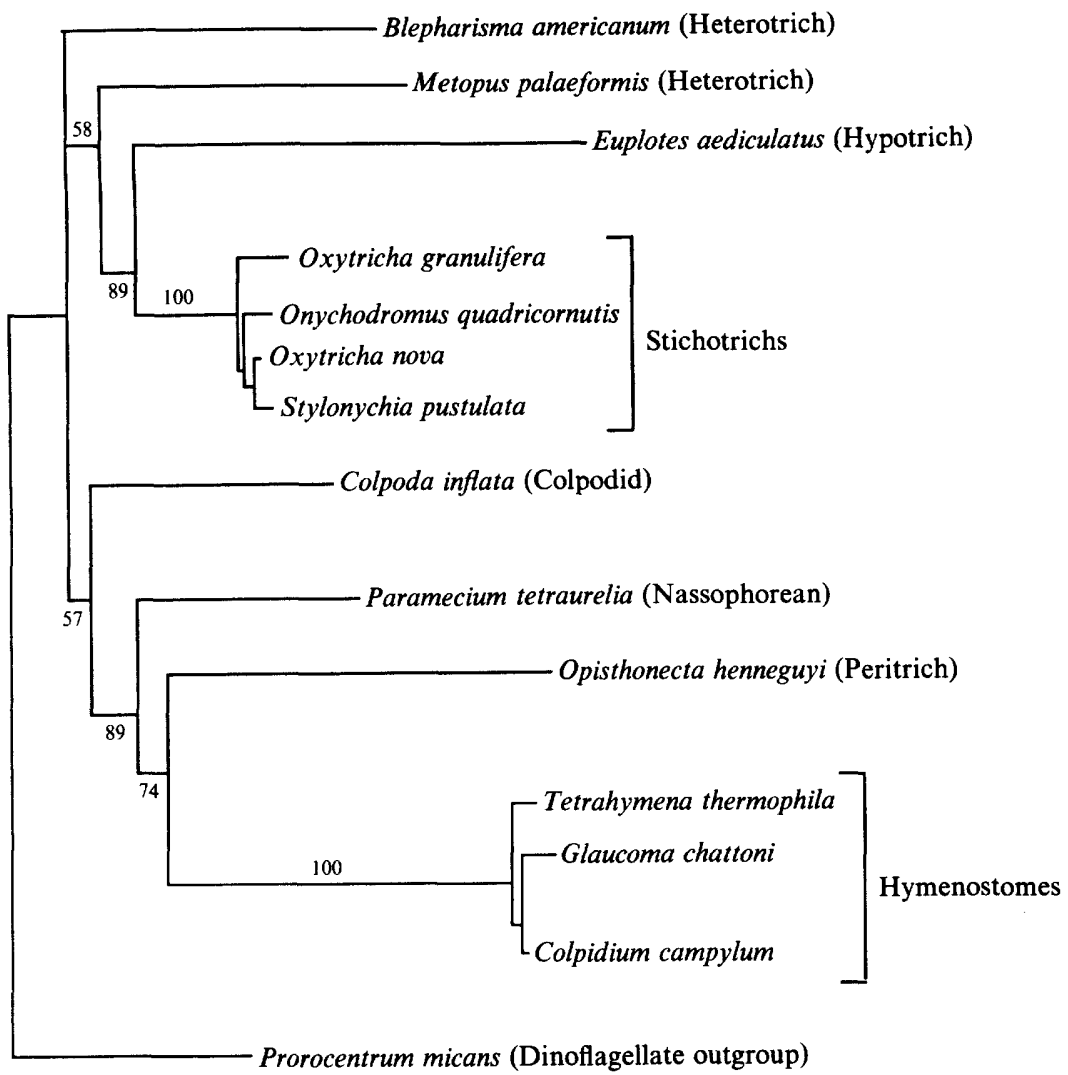

$0.02 K_{\text {nuc }}$
Fig. 2. Consensus phylogenetic tree showing the relationships of Metopus palaeformis to other ciliates and an outgroup, the dinoflagellate Prorocentrum micans. The tree is based on 100 bootstrap samplings of the data, each analysed using the Jukes \& Cantor (1969) correction and neighbourjoining (Saitou \& Nei, 1987) method. Figures reflect the number of times the group consisting of the species to the right of that node occurred among the trees. Names in parentheses are those currently in common use to denote higher taxa, i.e. class or subclass (Lynn \& Corliss, 1991). The scale represents 0.02 substitutions per sequence position ( $\left.K_{\text {nuc }}\right)$. previous work (Sogin et al., 1986; Schlegel et al., 1991). Interestingly, the linear invariants method (Lake, 1987) and its modification (Sidow \& Wilson, 1990) placed Euplotes significantly with the outgroup Prorocentrum micans. However, close examination of the Euplotes sequence suggested a substantial transversion bias towards uracil. This is a violation of the assumptions of the linear invariants method (and all other methods to some extent) and thus the results of these analyses should be treated with caution. The Euplotes sequence is also unusual in that it contains a number of insertions which are absent in the other ciliates (Sogin et al., 1986).

The heterotrichs are currently considered to be a monophyletic group (Lynn \& Corliss, 1991). The results of the present investigation provided only limited support for this hypothesis. All of the methods agreed that the heterotrichs Metopus palaeformis and Blepharisma americanum are deep-branching lineages. However, they appeared as sister taxa, with modest support $(71 \%$ of bootstrap replicates), in only the maximum parsimony analysis. The distance methods consistently placed Blepharisma americanum as a separate lineage at the root of the ciliates. This finding is in agreement with previous studies which reported Blepharisma as the deepestbranching ciliate (Greenwood et al., 1991a). Metopus palaeformis appeared with low to moderate support $(58 \%$ in neighbour joining Fig. 2, 70\% in the Fitch-Margoliash consensus tree - not shown) as a deep branch on the lineage leading to the stichotrichs (Fig. 2). The invariants methods were unable to resolve the relationship between the two heterotrichs with any confidence. It was thus impossible on the basis of the present data to decide if the heterotrichs form a mono- or paraphyletic group. Two approaches may help to resolve the relationships between these taxa. One is to sample additional species, especially among the heterotrichs and hypotrichs. The

Fig. 1. Photographs of the same field of whole fixed cells simultaneously probed with fluorescently-labelled oligonucleotides specific for either eukaryotes or Metopus palaeformis. (a) Phase-contrast image showing a single cell of Metopus palaeformis (M) among a variety of different eukaryotes, bacteria and archaeobacteria. (b) Epifluorescence image following specific excitation for the fluorescein-labelled eukaryote-specific probe. $(c)$ Epifluorescence image following specific excitation for the tetramethylrhodamine-labelled $M$. palaeformis probe. 
second approach would be to obtain more sequence data from the taxa already sampled. In this study the number of variable sites in the alignment of ciliate sequences (out of 1419 sites aligned and omitting Euplotes and Prorocentrum) was 417 , of which 261 were informative in the parsimony sense (Swofford, 1991). These data gave internal branches separating the heterotrichs and other taxa which were very short. It may thus prove impossible to resolve tree topology at this level using only smallsubunit sequences, and molecules which show a greater degree of variation (e.g. 28S rRNA or protein-coding genes) may be required. A relationship between the heterotrichs, hypotrichs and stichotrichs in the class Spirotrichea was proposed by Lynn \& Corliss (1991) on the basis of similarities in oral and somatic kinetids. Our data give qualified support for a clade containing Metopus, Euplotes (a hypotrich) and the stichotrichs.

The sequence for Metopus is the first to be published for an anaerobic ciliate. All of the analyses place Metopus close to aerobic ciliates and the distance methods consistently place it internal to the aerobe Blepharisma. The proximity of Metopus to aerobic ciliates is consistent with recent ultrastructural evidence which indicates that the hydrogenosomes of Metopus and other anaerobic ciliates are derived from mitochondria (Finlay \& Fenchel, 1989). The accumulating evidence thus suggests that anaerobic ciliates are derived from aerobic species.

The observation that two out of three of the deepest lineages in Fig. 2 are heterotrichs gives further support for the hypothesis that they branched off early in ciliate evolution (Greenwood et al., 1991a). Karyorelictean ciliates such as Loxodes and Protocruzia are the other candidates for the deepest-branching ciliates (Corliss, 1974; Lynn \& Corliss, 1991). An unpublished ciliate phylogeny based on partial large subunit sequences (cited in Schlegel, 1991) recovered Loxodes and Blepharisma as sister taxa. Further data from a representative sample of both groups are needed to fully resolve the association between the karyorelictids and the heterotrichs and to provide a clearer insight into ciliate evolution.

The amount of amplified template from the endosymbiont was sufficient to determine 416 bases of sequence from the base of stem 3 to the distal base of helix 18 on the Halobacterium cutirubrum secondary-structure model (Neefs et al., 1991). This covered one of the regions known to be most variable in prokaryotes, i.e. region V2 (Neefs et al., 1991). The symbiont sequence was $92 \%$ similar to the sequence of Methanobacterium formicicum for the same region (Lechner et al., 1985). The base differences comprised 15 transitions, 15 transversions and three insertions/deletions. All of the base differences occurred in regions known to be variable in archaeobacteria, and a plausible secondary structure (using

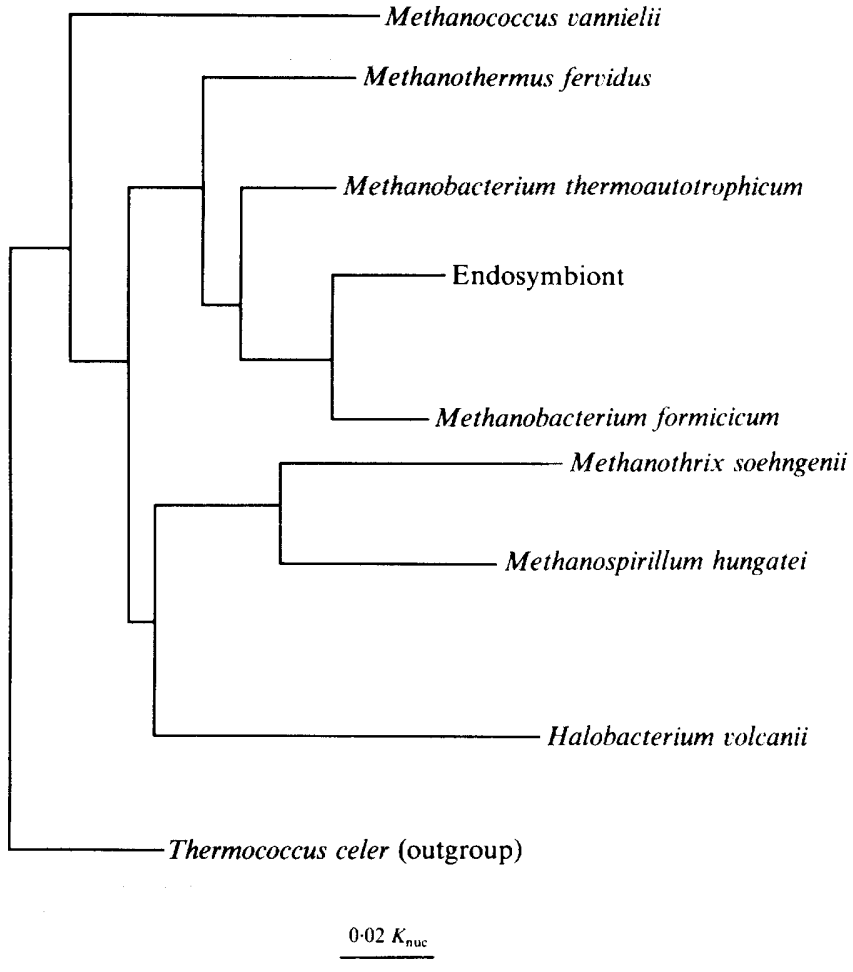

Fig. 3. Phylogenetic tree showing the relationships of the endosymbiont to representative archaeobacteria. The tree was generated using the Jukes \& Cantor (1969) correction and neighbour-joining method (Saitou \& Nei, 1987). The scale bar represents 0.02 substitutions per sequence position $\left(K_{\text {nuc }}\right)$.

models in Neefs et al., 1991) could be constructed. The endosymbiont sequence was compared to sequences from the same region for representatives of the Euryarchaeota. Fig. 3 shows a phylogenetic tree constructed using the Jukes \& Cantor (1969) correction and the neighbour-joining method (Saitou \& Nei, 1987). The symbiont is a member of the genus Methanobacterium and it is closely related to Methanobacterium formicicum. The assignment of the symbiont to Methanobacterium is supported by its morphology (Fig. 4) of electron-dense rod-shaped cells with conically pointed ends (Boone \& Mah, 1989). In the absence of phenetic data it is difficult to assign a taxonomic rank to the symbiont. However, the depth of branching between the symbiont and Methanobacterium formicicum suggests that they are closely related species.

To demonstrate that the new sequence was derived from the Metopus endosymbiont, two fluorescent probes were designed. The rRNA content of micro-organisms is proportional to growth rate and metabolic activity (DeLong et al., 1989). Since the physiological status and ribosome content of the symbiont were unknown, two probes were designed to bind to different regions of the symbiont rRNA and thus increase the signal. The probes 


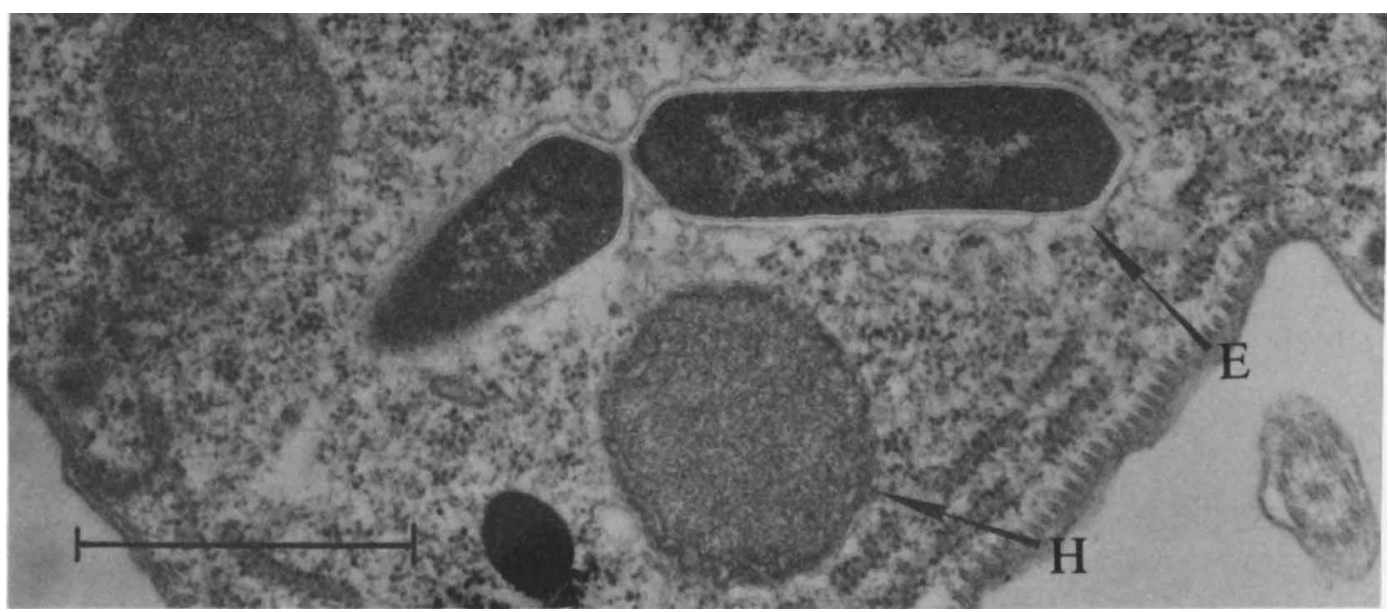

Fig. 4. Transmission electron micrograph of a dividing endosymbiont $(\mathrm{E})$ and a hydrogenosome $(\mathrm{H})$ in the ciliate Metopus palaeformis. Bar, $1 \mu \mathrm{m}$.
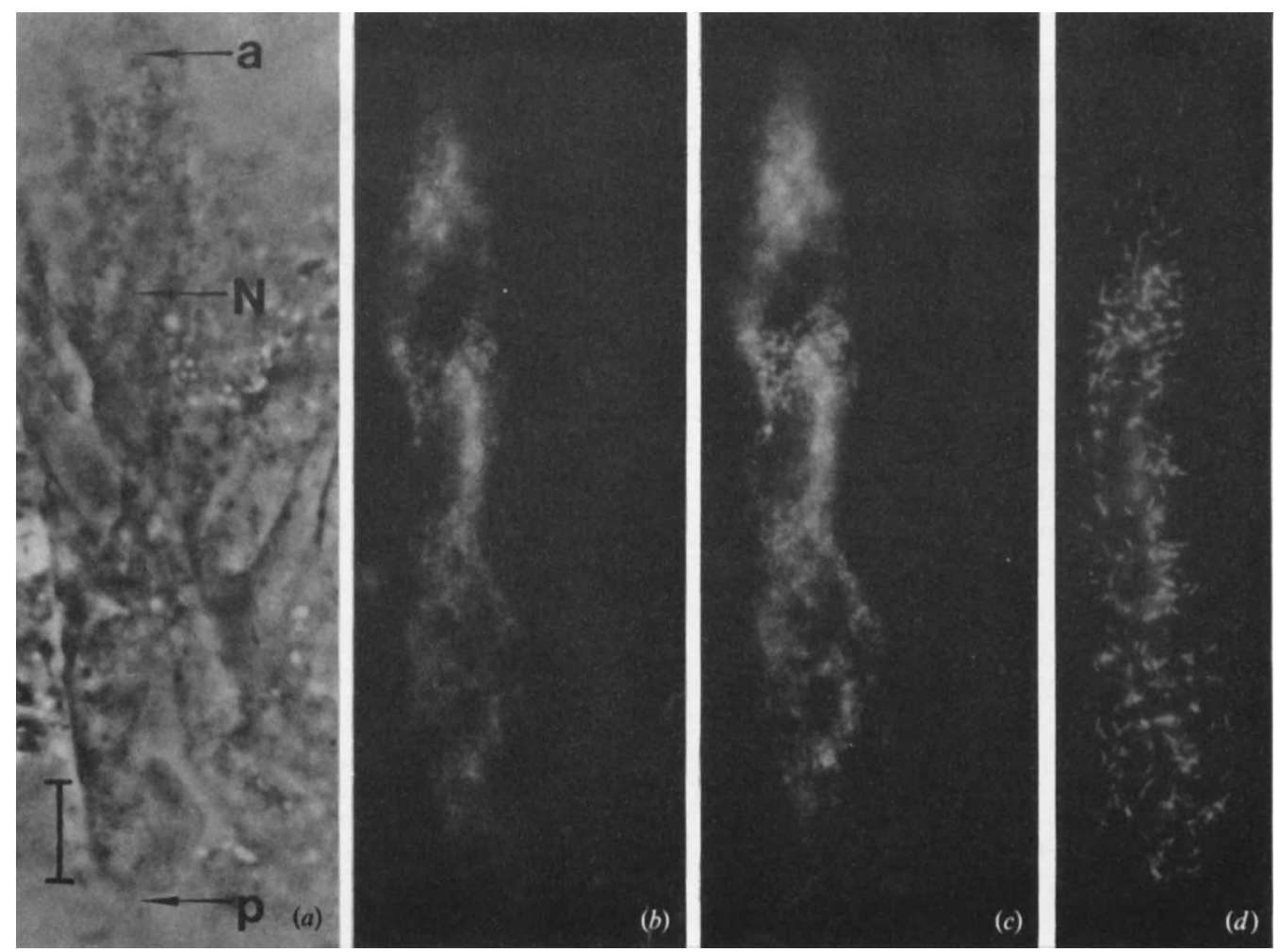

Fig. 5(a-c). Photographs of the same fixed whole cell of Metopus palaeformis simultaneously probed with archaeobacterial and symbiont-specific fluorescent oligonucleotide probes. ( $a$ ) Phase contrast image; ' $a$ ' and ' $p$ ' indicate the anterior and posterior limits of the ciliate and ' $N$ ' the macronucleus. The ciliate is surrounded by large numbers of unidentified micro-organisms and debris. $(b)$ Epifluorescence image of the same ciliate following specific excitation of the fluorescein-labelled archaeobacterial probe. (c) Epifluorescence image of the same ciliate following specific excitation of the tetramethylrhodamine-labelled symbiont-specific probes. (d) $\mathrm{F}_{420}$ autofluorescence in methanogens contained in another ciliate. Bar, $10 \mu \mathrm{m}$ (magnification is the same for parts $a-d$ ).

were targeted to sequences where there were significant differences between the endosymbiont, Methanobacterium formicicum and Metopus palaeformis. Fig. 5(a) shows a phase-contrast image of a single cell of Metopus palaeformis surrounded by large numbers of unidentified micro-organisms and debris. This cell was simultaneously probed with the fluorescein-labelled archaeobacterial probe (Fig. $5 b$ ) and the tetramethylrhodaminelabelled symbiont probes (Fig. 5c). All three probes clearly bind to the same bacterial-sized particulate 
material within the ciliate. Whereas the archaeobacterial probe gives faint signals from a small amount of the material surrounding the ciliate, the symbiont probes only bind to particles within the Metopus cell. The fluorescing particles have similar dimensions to the autofluorescing bacteria shown in another separately prepared ciliate (Fig. $5 d$ ). These results confirm that the amplified sequence is from the Metopus palaeformis endosymbiont. As far as we are aware this is the first direct evidence for an archaeobacterial endosymbiont. As expected, the combined fluorescence from the two symbiont probes exceeded the signal from the single archaeobacterial control probe. However, in both cases the high intensity of the fluorescence suggests that the symbionts are viable and metabolically active. This is supported by the fact that a dividing symbiont can be observed in the electron micrograph (Fig. 4). In contrast to the bacteria shown in Figs 4 and $5(d)$, it was not possible to discern clear rod-shaped particles using the fluorescent probes. This may have been due to glare caused by the high intensity of the probe fluorescence.

The functional significance of the Metopus palaeformis symbiosis is incompletely understood (Finlay \& Fenchel, 1991). Experimental inhibition of the methanogens did not lead to a detectable reduction in ciliate growth rate or yield (Finlay \& Fenchel, 1991). This is in contrast to the situation in Metopus contortus, where loss of its symbiont reduces the growth rate of the host (Fenchel \& Finlay, $1991 a, b)$. However, the bacteria in Metopus contortus are different from those in $M$. palaeformis since they do not react with the symbiont-specific probes (unpublished data). The potential benefits of the association for the Metopus palaeformis endosymbiont are clear. The symbiont is a member of the genus Methanobacterium and can probably (like cultured methanobacteria) obtain energy from coupling the oxidation of $\mathrm{H}_{2}$ to the reduction of carbonate (Jones et al., 1987; Boone \& Mah, 1989). Metopus palaeformis contains microbodies (Fig. 4) which are hydrogenase-positive (hydrogenosomes) and which release hydrogen during energy generation. It therefore seems plausible that the symbiont is benefiting from the $\mathrm{H}_{2}$ produced as an excretory product by the ciliate (Muller, 1988; Finlay, 1990).

This work was funded in part by the Natural Environment Research Council (B.J.F.) and the Department of Energy UK (through the Energy Technology Support Unit, Harwell, Contract E/5A/CON/ 1256/2099) to B. J.F. and T.M.E. The views and judgements expressed in this paper are those of the authors and do not necessarily reflect those of ETSU or the Department of Energy.

\section{References}

Amman, R. I., Krumholz, L. \& Stahl, D. A. (1990). Fluorescent oligonucleotide probing of whole cells for determinative, phylogenetic, and environmental studies in microbiology. Journal of Bacteriology 172, 762-770.
Amman, R. I., Springer, N., Ludwig, W., GorTZ, H. D. \& SCHLEIFER, K. H. (1991). Identification and phylogeny of uncultured bacterial symbionts. Nature, London 351, 161-164.

BOONE, D. R. \& MAH, R. A. (1989). Methanobacteriaceae. In Bergey's Manual of Systematic Bacteriology, vol. 3, pp. 2175-2178. Edited by J. T. Staley, M. P. Bryant, N. Pfennig \& J. G. Holt. Baltimore: Williams \& Wilkins.

CORLISS, J. O. (1974). Remarks on the composition of the large ciliate class Kinetofragminophora de Puytorac et al., 1974, and recognition of several new taxa therein, with emphasis on the primitive order Protociliatida n. ord. Journal of Protozoology 21, 207-220.

Delong, E. F., Wickham, G. S. \& Pace, N. R. (1989). Phylogenetic stains: ribosomal RNA based probes for the identification of single cells. Science 243, 1360-1363.

Edman, J. C., Kovacs, J. A., Masur, H., Santi, D. V., Elwood, H. J. \& Sogin, M. L. (1988). Ribosomal RNA sequences shows Pneumocystis carinii to be a member of the fungi. Nature, London 334, 519-522.

ELwOOD, H. J., OLSEN, G. J. \& SOGIN, M. L. (1985). The small subunit ribosomal RNA gene sequences from the hypotrichous ciliates Oxytricha nova and Stylonichia pustulata. Molecular Biology and Evolution 2, 399-410.

EMBLEY, T. M. (1991). The linear PCR reaction: a simple and robust method for sequencing amplified rRNA genes. Letters in Applied Microbiology 13, 171-174.

Fenchel, T. \& FinLay, B. J. (1990). Anaerobic free-living protozoa: growth efficiencies and the structure of anaerobic communities. FEMS Microbiology Ecology 74, 269-276

FenCheL, T. \& FINLAY, B. J. (1991a). The biology of free living anaerobic ciliates. European Journal of Protistology 26, 201-215.

Fenchel, T. \& Finlay, B. J. (1991 b). Endosymbiotic methanogenic bacteria in anaerobic ciliates: significance for the growth efficiency of the host. Journal of Protozoology 38, 18-22.

Fenchel, T., Perry, T. \& Thane, A. (1977). Anaerobiosis and symbiosis with bacteria in free-living ciliates. Journal of Protozoology 24, 154-163.

Finlay, B. J. (1990). Physiological ecology of free living protozoa. Advances in Microbial Ecology 11, 1-35.

Finlay, B. J. \& FenChEL, T. (1989). Hydrogenosomes in some anaerobic bacteria resemble mitochondria. FEMS Microbiology Letters 65, 311-314.

FinLAY, B. J. \& FeNCHEL, T. (1991). An anaerobic protozoon, with symbiotic methanogens, living in municipal landfill material. FEMS Microbiology Ecology 85, 169-180.

FITCH, W. M. \& Margoliash, E. (1967). Construction of phylogenetic trees. A method based on mutation distances as estimated from cytochrome $c$ sequences is of general applicability. Science 155, 279-284.

Fry, N. K., Rowthbottom, T. J., SAunders, N. A. \& Embley, T. M. (1991). Direct amplification and sequencing of the $16 \mathrm{~S}$ ribosomal DNA of an intracellular Legionella species recovered by amoebal enrichment from the sputum of a patient with pneumonia. FEMS Microbiology Letters 83, 165-168.

Gillespie, J. H. (1986). Rates of molecular evolution. Annual Review of Ecology and Systematics 17, 637-665.

Giovannoni, S. J., Delong, E. F., Olsen, G. J. \& Pace, N. R. (1988). Phylogenetic group-specific oligonucleotide probes for the identification of single microbial cells. Journal of Bacteriology 170, 720726.

Giovannoni, S. J., Britschgi, T. B., Moyer, C. L., \& Field, K. G. (1990). Genetic diversity in the Sargasso Sea bacterioplankton. Nature, London 345, 60-63.

Greenwood, S. J., Schlegel, M., Sogin, M. L. \& LynN, D. H. (1991 a). Phylogenetic relationships of Blepharisma americanum and Colpoda inflata within the phylum Ciliophora inferred from the complete small subunit rRNA gene sequences. Journal of Protozoology 38, 1-6.

Greenwood, S. J., SogIN, M. L. \& LYNN, D. H. (1991 b). Phylogenetic relationships within the class Oligohymenophora, phylum Ciliophora, inferred from the complete small subunit rRNA gene sequences of Colpidium campylum, Glaucoma chattoni and Opisthonecta henneguyi. Journal of Molecular Evolution 33, 163-174. 
JIN, L. \& NeI, M. (1991). Limitations of the evolutionary parsimony method of phylogenetic analysis. Molecular Biology and Evolution 7, 82-102.

Jones, W. J., Nagle, D. P. \& Whitman, W. B. (1987). Methanogens and the diversity of archaebacteria. Microbiological Reviews 51, $135-177$.

JUKES, T. H. \& CANTOR, C. R. (1969). Evolution of protein molecules. In Mammalian Protein Metabolism, pp. 21-132 Edited by H. N. Munro. New York: Academic Press.

LAKE, J. (1987). A rate-independent technique for analysis of nucleic acid sequences: evolutionary parsimony. Molecular Biology and Evolution 4, 167-191.

LECHNER, K., WICH, G. \& BoCK, A. (1985). The nucleotide sequence of the 16S rRNA gene and flanking regions from Methanobacterium formicium: on the phylogenetic relationship between methanogenic and halophilic archaebacteria. Systematic and Applied Microbiology 6, 157-163.

LyNN, D. \& CoRliss, J. (1991). Ciliophora. In Microscopic Anatomy of Invertebrates, vol. 1, Protozoa, pp. 333-467. Edited by F. Harrison \& J. O. Corliss. New York: Wiley-Liss.

Margulis, L., Corliss, J. O., Melkonian, M \& Chapman, D. J. (1989). Handbook of Protoctista. Boston: Jones \& Bartlett.

Medlin, L., Elwood, H. J., Stickel, S. \& Sogin, M. L. (1988). The characterisation of enzymatically amplified eukaryotic 16S-like rRNA coding regions. Gene 71, 491-499.

MULLER, M. (1988). Energy metabolism of protozoa without mitochondria. Annual Review of Microbiology 42, 465-488.

NeEFs, J.-M. \& DE WACHTER, R. (1991). A proposal for the secondary structure of a variable area of eukaryotic small ribosomal subunit RNA involving the existence of a pseudoknot. Nucleic Acids Research 18, 5695-5704.

Neefs, J.-M., VAN DE Peer, Y., De RiJK, P., Goris, A. \& De WACHTER, R. (1991). Compilation of small ribosomal subunit RNA sequences. Nucleic Acids Research 19 (Supplement), 1987-2015.

Nickrent, D. L. \& SARgent, M. L. (1991). An overview of the secondary structure of the V4 region of eukaryotic small-subunit ribosomal RNA. Nucleic Acids Research 19, 227-235.

Olsen, G. J., Lane, D. J., Giovannoni, S. J., Pace, N. R. \& Stahl, D. A. (1986). Microbial ecology and evolution: a ribosomal RNA approach. Annual Review of Microbiology 40, 337-365.

Pitcher, D., SAUnders, N. A. \& OwEN, R. J. (1989). Rapid extraction of bacterial genomic DNA with guanidium thiocyanate. Letters in Applied Microbiology 8, 151-156.

Saiki, R. K., Gelfand, D. H., Stoffel, S., Scharf, S. J., Higuchi, R. Horn, G. T., Mullis, K. B. \& ErLICH, H. A. (1988). Primer-directed enzymatic amplification of DNA with a thermostable DNA polymerase. Science 239, 487-491.

SAITOU, N. \& NEI, M. (1987). The neighbour joining method: a new method for constructing phylogenetic trees. Molecular Biology and Evolution 4, 406-425.
SCHLEGEL, M. (1991). Protist evolution and phylogeny as discerned from small subunit ribosomal RNA sequence comparisons. European Journal of Protistology 27, 207-219.

Schlegel, M., Elwood, H. J. \& Sogin, M. L. (1991). Molecular evolution in hypotrichous ciliates: sequence of the small subunit ribosomal RNA genes from Onychodromus quadricornutus and Oxytricha granulifera (Oxytrichidae, Hypotrichida, Ciliophora). Journal of Molecular Evolution 32, 64-69.

Sidow, A. \& Wilson, A. C. (1990). Compositional statistics: an improvement of evolutionary parsimony and its application to deep branches in the tree of life. Journal of Molecular Evolution 31, 51-68.

Sogin, M. L., Swanton, M. T., Gunderson, J. H. \& Elwood, H. J. (1986). Sequence of the small subunit ribosomal RNA gene from the hypotrichous ciliate Euplotes aediculatus. Journal of Protozoology 33, 26-29.

StaHL, D. A. \& Amman, R. I. (1991). Development and application of nucleic acid probes in bacterial systematics. In Nucleic Acid Techniques in Bacterial Systematics, pp. 205-248. Edited by E. Stackebrandt \& M. Goodfellow. Chichester: John Wiley.

Stahi, D. A., Flesher, B., Mansfield, H. R. \& Montgomery, L. (1988). Use of phylogenetically based hybridization probes for studies of ruminal microbial ecology. Applied and Environmental Microbiology 54, 1079-1084.

SWOFFFORD, D. (1991). PAUP: phylogenetic analysis using parsimony, version 3.0. Computer program distributed by the Illinois Natural History Survey, Champaign, Illinois, USA.

Van Bruggen, J. J. A., Zwart, K. B., Van Assema, R. M., Stumm, C. K. \& VoGels, G. D. (1984). Methanobacterium formicicum, an endosymbiont of the anaerobic ciliate Metopus striatus McMurrich. Archives of Microbiology 139, 1-7.

Van Bruggen, J. J. A., Zwart, K. B., Hermans, J. G. F., Van Hove, E. M., Stumm, C. K. \& Vogels, G. D. (1986). Isolation and characterisation of Methanoplanus endosymbiosus sp. nov., an endosymbiont of the marine sapropelic ciliate Metopus contortus Quennerstedt. Archives of Microbiology 144, 367-374.

WAGENER, S. \& PfenNig, N. (1987). Monoxenic culture of the anaerobic ciliate Trimyema compressum Lackey. Archives of Microbiology 149, 4-11.

Wagener, S., Stumm, C. K. \& Vogels, G. D. (1986). Electromigration, a tool for studies on anaerobic ciliates. FEMS Microbiology Ecology 38, 197-203.

WoEsE, C. R. (1987). Bacterial classification. Microbiological Reviews 51, 221-271.

Woese, C. R., KandleR, O. \& Wheelis, M. L. (1990). Towards a natural system for organisms: proposal for the Domains Archaea, Bacteria and Eucarya. Proceedings of the National Academy of Sciences of the United States of America 87, 4576-4579. 